\title{
ĐÁNH GIÁ KẾT QUẢ ĐIỀU TRI ĐAU THẦN KINH TỌA DO THOÁT VỊ ĐĨA ĐỆM BẰNG TIÊM COLLAGEN GUNA
}

\section{TÓM TẮT}

Từ năm 2010, trong nền y văn thế giới đã đề câp đến phương pháp tiêm Collagen điều trị đau dây thần kinh tọa do thoát vị đĩa dệm cột sống thắt lưng. Liệu pháp sử dụng Collagen điểu trị các bệnh lý bị gây ra bởi những sự phá hủy hoặc quá tải của tất cả các mô của hệ thống cơ xương khớp. Collagen Guna cung cấp chất nền tropocollagen để cơ thể tổng hợp Collagen cũng như kích thích nguyên bào sợi tăng sinh Collagen nội sinh giúp phục hồi, thay thế, củng cố và xây dựng cấu trúc mô học của sợi Collagen tại các tổ chức có Collagen như gân, dây Chằng, màng bao khớp, vòng xơ sụn.... Mục tiêu: Đánh giá kết quả, tác dụng không mong muốn của tiêm Collagen trong điều trị đau thần kinh tọa do thoát vị đĩa đệm. Đối tượng và phương pháp nghiên cứu: Nghiên cứu tiến cứu can thiệp theo dõi dọc trong 8 tuần với 30 bệnh nhân đau thần kinh tọa do thoát vị đĩa đệm được tiêm collagen MD - Lumbra, tiêm cạnh cột sống 4 vị trí và MD Ischail tiêm dọc theo đường theo đường đi của dây thần kinnh tọa 4 vị trí với liệu trình 2 tuần đầu tiêm 2 lần mỗi lần cách nhau 3 ngày, 6 tuần tiếp theo tiêm mỗi tuần 1 lần. Kết quả: Sau 8 tuần điều trị, có sự cải thiện thang điểm VAS giảm từ $6.9 \pm 1.1$ xuống $1 \pm$ $0.8(p<0,05)$, đấu hiệu Lasegues (độ) tăng sau điều trị, bên phải $22.3 \pm 10$ độ bên trái $20.3 \pm 7$ độ ( $p<$ $0,05)$, đô giãn côtt sống thắt lưng (NP Schober) tăng từ $2.4 \pm 0.8 \mathrm{~cm}$ lên $5.1 \pm 0.3 \mathrm{~cm}$. Sự cải thiện khoảng cách tay đất trung bình $11.2 \pm 5 \mathrm{~cm}$ giảm xuống còn $1.27 \pm 1.2 \mathrm{~cm}(p<0.05)$. Sự cải thiện các chức năng sinh hoạt hàng ngày tăng từ $1.1 \pm 0.3$ lên $3.9 \pm 0.2$ $(p<0.05)$. Không có bệnh nhân nào có phản ứng dị ứng (ngứa sau tiêm), nhiễm trùngcũng như shock phản vệ̂, không có bệnh nhân nào đau tăng sau tiêm. Kết luận: Tiêm collagen trong điêu trị đau dây thân kinh tọa đo thoát vị đĩa đệm có hiệu quả tốt và không gặp các tác dụng phụ khổng mong muốn nào.

Tư khóa: Tiêm Collagen trong điêu trị đau dây thần kinh tọa đo thoát vị đĩa đệm.

\section{SUMMARY}

ASSESSMENT OF THE EFFECTIVENESS OF NERVE PAIN TREATMENT CAUSED BY HERNIATED DISC

WITH GUNA COLLAGEN INJECTION

Since 2010, the world medical literature has mentioned the method of collagen injection to treat sciatica pain caused by lumbar disc herniation. Collagen therapy treats pathologies caused by the destruction or overload of all tissues of the

*Bênh viện đa khoa Đức Giang

Chịu trách nhiệm chính: Nguyển Đình Hiện

Email: Hienhungha@gmail.com

Ngày nhận bài: 17.5.2021

Ngày phản biên khoa hoc: 2.7.2021

Ngày duyệt bài: 15.7.2021

\section{Nguyễn Đình Hiện*}

musculoskeletal system. Collagen Guna provides tropocollagen substrate for the body to synthesize Collagen as well as stimulates fibroblasts to increase endogenous Collagen to help restore, replace, strengthen and build histological structure of Collagen fibers in collagen-containing organizations. Such as tendons, ligaments, joint capsule, fibrocartilage, muscle and extracellular matrix.... Objective: To evaluate the effectiveness and side effects of collagen injection in the treatment of sciatica. Methods: Prospective, interventional study with longitudinal follow-up for 8 weeks with 30 patients with sciatica caused by disc herniation receiving MD-Lumbar injection, 4-position para spinal injection and MD Ischia injection along the path of the sciatic nerve 4 positions with 2 treatments weekly ( 3 days apart) for the first 2 weeks and 1 treatment weekly for next 6 consecutive weeks. Results: After 8 weeks of treatment, there was an improvement in VAS score from $6.9 \pm 1.1$ to $1 \pm 0.8(p<0.05)$, Lasègue sign (degrees) increased after treatment, right side $22.3 \pm$ 10 degrees left $20.3 \pm 7$ degrees $(p<0.05)$. Lumbar spine extension (NP Schober) increased from $2.4 \pm$ $0.8 \mathrm{~cm}$ to $5.1 \pm 0.3 \mathrm{~cm}$. Average hand-to-hand distance improvement $11.2 \pm 5 \mathrm{~cm}$ decreased to $1.27 \pm 1.2 \mathrm{~cm}$ $(p<0.05)$. The improvement in daily operation function increased from $1.1 \pm 0.3$ to $3.9 \pm 0.2(p<$ 0.05 ). There are no patient had allergic reaction (postinjection pruritus), infection as well as anaphylaxis, no patient had increased pain after injection. Conclusion: The injections of Collagen MDs are effective method in treatment sciatica caused by herniated discs and there were no side effect were observed.

Key words: GuNa Collagen injection in nerve pain treatment caused by herniated disc.

\section{I. ĐăTT VẤN ĐỀ}

Điều trị đau dây thần kinh tọa do thoát vị đĩa đệm (TVĐĐ) hiện nay có nhiều phương pháp khác nhau. Các phương pháp chính là điều trị thuốc (nhóm thuốc giảm đau, chống viêm không steroid, thuốc giãn cơ), tiêm corticoid ngoài màng cứng, phục hồi chức năng (kéo giãn cột sống thắt lưng, các bài tập vận động...) và phương pháp điêu trị ngoại khoa.

Từ năm 2010, trong nền y văn thễ giới đã đề cập đến phương pháp tiêm Collagen điêu trị đau dây thần kinh tọa do TVĐĐ cột sống thắt lưng.

Liệu pháp sử dụng Collagen để điêu trị các bệnh lý bị gây ra bởi những sự phá hủy hoặ̆ quá tải của tất cả các mô của hệ thông cơ xương khớp và hệ thống da bì, sửa chữa, tái tạo phục hồi chức nằng của mô bị tổn thương. Guna MDs Collagen cung cấp chất nền tropocollagen để cơ thể tổng hợp Collagen cũng như kích thích 
nguyên bào sợi tăng sinh Collagen nội sinh giúp phục hồi, thay thế, củng cố và xây dựng cấu trúc mô học của sợi Collagen tại các tổ chức có Collagen như gân, dây trằng, màng bao khớp, vòng $x \sigma$ sụn ....

Ơ Việt Nam Guna MDs Collagen có từ năm 2016 nhưng cho đến nay vẫn chưa có nghiên cứu nào đánh giá hiệu quả của phương pháp pháp tiêm Collagen điều trị đau dây thân kinh tọa do TVĐĐ cột sống thắt lưng. Do do chúng tôi tiến hành nghiên cứu đề tài: "Đánh giá kêt quả điều tri đau thần kinh toa do thoát vi đĩa đêm bằng tiêm Collagen tại bệnh viện đa khoa Đức Giang" Nhằm mục tiêu đánh giá kết quả, tác dụng không mong muốn của tiêm Collagen trong điều trị đau thân kinh tọa.

\section{II. ĐỐI TƯợNG VÀ PHƯƠNG PHÁP NGHIÊN CỨU \\ 2.1 Đối tượng nghiên cứu}

2.1.1. Địa điểm và thời gian nghiên cứu:

- Địa điểm nghiên cứu: Đớn nguyên cơ xương khớp bệnh viện đa khoa Đức Giang.

- Thời gian nghiên cứu từ tháng 1 năm 2019 đến tháng 10 năm 2019

2.1.2 Chọn mẫu. Sử dụng mẫu thuận tiện trong nghiên cứu với số lượng tối thiểu 30 bệnh nhân.

\section{KẾT QUẢ NGHIÊN CỨU}

\section{Bảng 3.1. Mốt số đặc điểm lâm sàng trước và sau điều trị.}

\begin{tabular}{|c|c|c|c|c|c|c|c|c|c|}
\hline \multirow{2}{*}{\multicolumn{2}{|c|}{ Đặc điểm lâm sàng }} & \multicolumn{2}{|c|}{ T1 } & \multicolumn{2}{|c|}{ T2 } & \multicolumn{2}{|c|}{ T3 } & \multicolumn{2}{|c|}{ T4 và T5 } \\
\hline & & $\mathbf{n}$ & $\%$ & $\mathbf{n}$ & $\%$ & $\mathbf{n}$ & $\%$ & $\mathbf{N}$ & $\%$ \\
\hline \multirow{2}{*}{$\begin{array}{l}\text { Đau tăng khi } \\
\text { ho hắt hơi }\end{array}$} & Có & 23 & $76.7 \%$ & 16 & $53.3 \%$ & 1 & $3.3 \%$ & 0 & $0 \%$ \\
\hline & Không & 7 & $23.3 \%$ & 14 & $46.7 \%$ & 9 & $96.7 \%$ & 30 & $100 \%$ \\
\hline \multirow{2}{*}{ Đau cơ học } & Có & 28 & $93.3 \%$ & 18 & $60 \%$ & 3 & $10 \%$ & 0 & $0 \%$ \\
\hline & Không & 2 & $6.7 \%$ & 12 & $40 \%$ & 27 & $90 \%$ & 30 & $100 \%$ \\
\hline \multirow{2}{*}{ Đau kiểu viêm } & Có & 9 & $30 \%$ & 6 & $20 \%$ & 1 & $3.3 \%$ & 0 & $0 \%$ \\
\hline & Không & 21 & $70 \%$ & 24 & $80 \%$ & 29 & $96.7 \%$ & 30 & $100 \%$ \\
\hline \multirow{2}{*}{$\begin{array}{c}\text { Tư thế chống } \\
\text { đau }\end{array}$} & Có & 30 & $100 \%$ & 18 & $60 \%$ & 3 & $10 \%$ & 0 & $0 \%$ \\
\hline & Không & 0 & $0 \%$ & 12 & $40 \%$ & 27 & $90 \%$ & 30 & $100 \%$ \\
\hline \multirow{2}{*}{$\begin{array}{c}\text { Co cứng cớ } \\
\text { cạnh cột sống }\end{array}$} & Có & 24 & $80 \%$ & 14 & $46.7 \%$ & 2 & $6.7 \%$ & 0 & $0 \%$ \\
\hline & Không & 6 & $20 \%$ & 16 & $53.3 \%$ & 28 & $93.3 \%$ & 30 & $100 \%$ \\
\hline \multirow{2}{*}{$\begin{array}{l}\text { Mất đường } \\
\text { cong sinh lý }\end{array}$} & Có & 22 & $73.3 \%$ & 15 & $50 \%$ & 5 & $16.7 \%$ & 0 & $0 \%$ \\
\hline & Không & 8 & $26.7 \%$ & 15 & $50 \%$ & 25 & $83.3 \%$ & 30 & $100 \%$ \\
\hline
\end{tabular}

Nhân xét: Các triệu chứng lâm sàng giảm dân theo từng thời kỳ điều trị, đặc biệt sau thời gian điều trị T4 và T5 100\% hết các triêu chứng như đau tăng khi ho hắt hơi, đau cơ hoc, đau kiểu viêm. $100 \%$ không còn tư thế chống đau. $100 \%$ không còn đấu hiệu mất đường cong sinh lý cột sống thắt lưng, đấu hiệu co cứng cơ cạnh cột sống. Co cứng cơ cạnh cột sống

Bảng 3.2. Sự cải thiện về độ giãn cột sống thẳt lưng, chỉ sồ oswestry, đấu hiệu lasegues qua các thời điểm điều trị.

\begin{tabular}{|c|c|c|c|c|}
\hline \multirow{2}{*}{ Thời điểm } & \multirow{2}{*}{ Độ giãn CSTL } & \multirow{2}{*}{ Oswestry } & \multicolumn{2}{|c|}{ Lasegues (độ) } \\
\cline { 2 - 5 } & $\bar{X} \pm$ SD & $\bar{X} \pm$ SD & \multicolumn{2}{|c|}{ Trái } \\
\hline T1 & $2.4 \pm 0.8$ & $1.1 \pm 0.3$ & $67.6 \pm 10$ & $69.6 \pm 7.8$ \\
\hline T2 & $3.1 \pm 0.7$ & $1.8 \pm 0.5$ & $75.2 \pm 7$ & $77.5 \pm 6$ \\
\hline T3 & $3.8 \pm 0.7$ & $2.5 \pm 0.5$ & $81.6 \pm 5$ & $8.2 \pm 5.1$ \\
\hline
\end{tabular}




\begin{tabular}{|c|c|c|c|c|}
\hline T4 & $4.5 \pm 0.6$ & $3.2 \pm 0.5$ & $87.1 \pm 3$ & $87.1 \pm 3.6$ \\
\hline T5 & $5.1 \pm 0.3$ & $3.9 \pm 0.2$ & $90 \pm 0$ & $90 \pm 0$ \\
\hline Điếm chênh $\Delta_{2-1}$ & $0.7 \pm 0.5$ & $0.7 \pm 0.5$ & $7.6 \pm 5.6$ & $7.8 \pm 4.4$ \\
\hline Điếm chênh $\Delta_{3-2}$ & $0.7 \pm 0.5$ & $0.7 \pm 0.4$ & $6.4 \pm 5$ & $4.6 \pm 3.4$ \\
\hline Điếm chênh $\Delta_{4-3}$ & $0.7 \pm 0.5$ & $0.7 \pm 0.4$ & $5 \pm 3$ & $5 \pm 3.1$ \\
\hline Điếm chênh $\Delta_{5-1}$ & $2.7 \pm 0.8$ & $2.8 \pm 0.3$ & $22.3 \pm 10$ & $20.3 \pm 7$ \\
\hline$p(2-1)$ & \multicolumn{4}{|c|}{$<0.05$} \\
\hline$p(3-2)$ & \multicolumn{4}{|c|}{$<0.05$} \\
\hline$p(4-3)$ & \multirow{2}{*}{\multicolumn{4}{|c|}{$<0.05$}} \\
\hline$p(5-1)$ & & \multicolumn{3}{|c|}{$<0.05$} \\
\hline
\end{tabular}

Nhận xét: Độ giãn CSTL, chỉ số Oswestry, đấu hiệu Lasegues (độ) đều tăng so với đợt tiêm trước có sự khác biệt giữa các đợt điều trị, sự khác biệt có ý nghĩa thống kê $P<0.05$.

Bảng 3.3. Sự cải thiện chỉ số VAS, khoảng cách tay đất qua các thời điểm điều trị

\begin{tabular}{|c|c|c|}
\hline \multirow{2}{*}{ Thời điểm } & VAS & $\begin{array}{c}\text { Khoảng các| } \\
\text { tay đất }\end{array}$ \\
\cline { 2 - 3 } & $\overline{\boldsymbol{X}} \pm \mathrm{SD}$ & $\overline{\boldsymbol{X}} \pm \mathrm{SD}$ \\
\hline T1 & $6.9 \pm 1.1$ & $11.2 \pm 5$ \\
\hline T2 & $5.3 \pm 1$ & $8 \pm 3.9$ \\
\hline T3 & $4 \pm 0.9$ & $5.7 \pm 2.8$ \\
\hline T4 & $2.2 \pm 0.8$ & $3.2 \pm 2.1$ \\
\hline T5 & $1 \pm 0.8$ & $1.27 \pm 1.2$ \\
\hline Điếm chênh TB $\Delta_{1-2}$ & $1.6 \pm 0.7$ & $3.2 \pm 1.6$ \\
\hline
\end{tabular}

\begin{tabular}{|c|c|c|}
\hline Điểm chênh TB $\Delta_{2}-3$ & $1.3 \pm 0.6$ & $2.3 \pm 1.4$ \\
\hline Điếm chênh TB $\Delta_{3}-4$ & $1.7 \pm 0.5$ & $2.5 \pm 1$ \\
\hline Điếm chênh TB $\Delta_{4}-5$ & $1.4 \pm 0.6$ & $1.9 \pm 1.2$ \\
\hline Điếm chênh TB $\Delta_{1}-5$ & $6.1 \pm 1.1$ & $9.9 \pm 4.1$ \\
\hline $\mathrm{P}(1-2)$ & $<0.05$ \\
\hline $\mathrm{P}(2-3)$ & $<0.05$ \\
\hline $\mathrm{P}(3-4)$ & $<0.05$ \\
\hline $\mathrm{P}(4-5)$ & $<0.05$ \\
\hline $\mathrm{P}(1-5)$ & $<0.05$ \\
\hline
\end{tabular}

Nhận xét: Chỉ số VAS và khoảng cách tay đất giảm sau điều trị tại các thời điểm có ý nghĩa thống kê $(\mathrm{p}<0.05)$

Bảng 3.4. Phân bố bệnh nhân theo tác dụng không mong muốn

\begin{tabular}{|c|c|c|c|c|c|c|c|c|c|c|}
\hline \multirow{2}{*}{ TD không mong muốn } & \multicolumn{3}{|c|}{ T1 } & \multicolumn{2}{|c|}{ T2 } & \multicolumn{2}{|c|}{ T3 } & \multicolumn{2}{|c|}{ T4 } & \multicolumn{2}{|c|}{ T5 } \\
\cline { 2 - 11 } & $\mathbf{N}$ & $\mathbf{\%}$ & $\mathbf{N}$ & $\mathbf{\%}$ & $\mathbf{N}$ & $\mathbf{\%}$ & $\mathbf{N}$ & $\mathbf{\%}$ & $\mathbf{N}$ & $\mathbf{\%}$ \\
\hline Shock phản vệ & 0 & 0 & 0 & 0 & 0 & 0 & 0 & 0 & 0 & 0 \\
\hline Phản ứng dị ứng & 0 & 0 & 0 & 0 & 0 & 0 & 0 & 0 & 0 & 0 \\
\hline Nhiêm trùng vị trí tiêm & 0 & 0 & 0 & 0 & 0 & 0 & 0 & 0 & 0 & 0 \\
\hline Đau tăng sau tiêm & 0 & 0 & 0 & 0 & 0 & 0 & 0 & 0 & 0 & 0 \\
\hline
\end{tabular}

Nhận xét: Không có tác dụng phụ như đau tăng sau tiêm, nhiềm trùng vị trí tiêm, phản ứng dị ứng cũng như shock phản vệ khi tiêm.

\section{BÀN LUẬN}

4.1. Sự cải thiên mức độ đau. Biểu hiện sớm nhất của đau dây thần kinh toạ do thoát vị đĩa đệm cột sống thắt lưng là đau và đây cũng chính là nguyên nhân khiến bệnh nhân phải nhập viện điêu trị, đau cũng chính là yếu tố chính gây hạn chế vận động, làm ảnh hưởng đến chất lượng cuộc sống của người bệnh. Đau trong thoát vị đĩa đệm cột sống thắt lưng là đau do sự chèn ép vào dây chằng dọc sau, khi bao rễ thần kinh bị kích thích sẽ gây phản xạ co thắt mạch, thiếu máu cũng có thể gây đau, do phù rễ thần kinh và khi rễ thần kinh bị chèn ép trong lỗ liên hợp gây phù nề. Tuỳ vào thoát vị đĩa đệm, đau có thể biểu hiện tại chỗ thắt lưng hoặc lan theo rễ thần kinh từ thắt lưng xuống tận bàn ngón chân.

Trong nghiên cứu của chúng tôi điểm VAS trước điều trị trung bình là $6.9 \pm 1.1$ tại thời điểm $\mathrm{T} 2$ giảm còn $5.3 \pm 1$, tai thời điểm T3 giảm còn $4 \pm 0.9$, tại thời điểm T4 giảm còn $2.2 \pm 0.8$, tai thời điểm T5 giảm còn $1 \pm 0.8$, điểm số đau trung bình giảm có ý nghĩa thống kê với $p<0,05$.

Nghiên cứu của chúng tôi cũng tương đồng với nghiên cứu của K. Pavelka, R. Svobodová, H. Jarošová (2012) nghiên cứu trên 36 bệnh nhân tiêm MD lumbar đau cột sống thắt lưng thấy điểm VAS trung bình khi vận động giảm từ 7.1 \pm 1.3 điểm xuống $3.7 \pm 2.3$ điểm ở tuần thứ 5 $(P<0.05)$ VAS trung bình khi nghỉ ngơi giảm từ $5.9 \pm 1.6$ xuống còn $2.8 \pm 2.4(P<0.05)$. Kết quả điều trị rất tốt chiếm tỷ lệ $66.7 \%$, tốt chiếm tỷ lệ $25 \%$ trung bình chiếm tỷ lệ $8.3 \%$. Kết luận của nghiên cứu cho thấy MD Lumbar có hiệu quả trong điêuu trị.

4.2. Sự cải thiện độ Lasegue. Nghiệm pháp Lasegue là 1 nghiệm pháp thường dùng trong trong thăm khám lâm sàng các bệnh cơ xương khớp nói chung và đau dây thần kinh toạ nói riêng. Nghiệm pháp Lasegue là góc được tạo bởi mặt giường và chân bệnh nhân đến khi đau, thường được đánh giá là dương tính khi góc độ Lasegue $<85^{\circ}$. 
Đánh giá độ Lasegue trước và sau điều trị sẽ giúp đánh giá khách quan hiệu quả điều trị.

Trong nghiên cứu của chúng tối đấu hiệu Lasegues (độ) đều tăng so với trước điều trị sự khác biệt có ý nghĩa thống kê $\mathrm{P}<0.05$. Trước tiêm thời điểm $T 2$ điểm tăng trung bình với bên phải tăng $7.6 \pm 5.6$ độ bên trái tăng $7.8 \pm 4.4$ độ, trước tiêm thời điểm T3 điểm tăng trung bình với bên phải tăng $6.4 \pm 5$ độ bên trái tăng 4.6 × 3.4 độ, trước tiêm thời điểm T4 điểm tăng trung bình với bên phải tăng $5 \pm 3$ độ bên trái tăng $5 \pm 3.1$ độ và đặc biệt so sánh tại thời điểm bắt đầu tiêm đến thời điểm T5 thì điểm tăng trung bình với bên phải tăng $22.3 \pm 10$ độ bên trái tăng $20.3 \pm 7$ độ.

4.3. Sự cải thiện độ giãn cột sống thắt lưng (NP Schober). Chúng tôi đánh giá chức năng vận động cột sống thắt lưng của các bệnh nhân thông qua độ giãn cột sống thắt lưng (Nghiệm pháp Schober) và tầm vận động cột sống thắt lưng (2 động tác chính là gấp và duỗi cột sống thắt lưng). Trong TVĐĐ cột sống thắt lưng, sự hạn chế chức năng vận động cột sống thắt lưng là hậu quả của triệu chứng đau. Ngoài ra còn do co rút các cơ cạnh sống, di lệch khớp đốt sống, co kéo các tổ chức liên kết bao gồm gân cơ, dây chằng, bao khớp... dẫn đến hạn chế tầm vận động CSTL

Qua bảng 3.8 theo sự cải thiện độ giãn CSTL chúng tôi thấy đa số các bệnh nhân có sự thiện đáng kể, ở thời điểm T2 độ giãn CSTL trung tăng từ $2.4 \pm 0.8$ lên $3.1 \pm 0.7$, ở thời điểm T3 độ giãn CSTL trung tăng lên $3.8 \pm 0.7$, ở thời điểm T4 độ giãn CSTL trung tăng lên $4.5 \pm 0.6$ ở thời điểm T5 độ giãn CSTL trung tăng lên $5.1 \pm 0.3$. tăng độ giãn CSTL so với các đợt điều trị trước điều trị sự tăng có ý nghĩa thống kê $\mathrm{P}<0.05$.

4.4. Sự cải thiện khoảng cách tay đất. Cùng với độ giãn CSTL, tầm vận động cột sống, góc độ Lasegue,... thì nghiệm pháp tay đất là một trong số những tiêu chí đo lường về hiệu quả điều trị của bệnh nhân TVĐĐ. Nghiệm pháp tay đất thể hiện khả năng vận động, khả năng gập của cột sống và độ mềm mại của các tổ chức phần mềm, gân, cơ cột sống thắt lưng.

Trong nghiên cứu của chúng tôi, ở thời điểm trước tiêm đa số bệnh nhân nghiên cứu có khoảng cách tay đất trung bình $11.2 \pm 5$ sau tiêm tại thời điểm T2 giảm xuống còn $8 \pm 3.9$, sau tiêm tại thời điểm T3 giảm xuống còn $5.7 \pm 2.8$, sau tiểm tại thời điểm $T 4$ giảm còn $3.2 \pm 2.1$ và sau tiêm tại thời điểm $T 5$ còn $1.27 \pm 1.2$, khoảng cách tay đất giảm sau điều trị tại các thời điểm có ý nghĩa thống kê $(p<0.05)$.
Quá trình điều trị, do mức độ đau giảm dần, mức độ co cơ cột sống và khả năng vận động CSTL tốt lên, do đó khoảng cách tay đất cũng tốt dần lên.

4.5. Đánh giá sự cải thiện các chức năng sinh hoạt hàng ngày. Đau và hạn chế tầm vận động cột sống thắt lưng ở bệnh nhân đau thần kinh toạ do thoát vị đĩa đệm biểu hiện bằng những hạn chế trong lao động, sinh hoạt hàng ngày của bệnh nhân. Cũng chính đau và những hạn chế trong lao động, sinh hoạt hàng ngày là nguyên nhân khiến bệnh nhân phải nhập viện. Để đánh giá ảnh hưởng của thoát vị đĩa đệm CSTL đến các CNSH, chúng tôi lựa chọn 4 trong số 10 câu hỏi trong bộ câu hỏi Oswestry Low Back Pain Disability Questionaire bao gồm chăm sóc cá nhân, nhấc vật nặng, đi bộ, ngồi.

Kết quả nghiên cứu của chúng tôi thông qua bảng 3.8 cho thấy có sự cải thiện chức năng sinh hoạt hàng ngày sau tiểm thể hiện qua điểm số trung bình theo bộ câu hỏi Oswestry, trước điêu trị là $1.1 \pm 0.3$ sau điều trị tại thời điểm T2 tăng là $1.8 \pm 0.5$, sau điều trị tại thời điểm T3 tăng là $2.5 \pm 0.5$, sau điều trị tại thời điểm T4 tăng là 3.2 \pm 0.5 , sau điều trị tại thời điểm T5 tăng là $3.9 \pm$ 0.2 . chỉ số Oswestry tăng so với thời điểm trước điều trị sự khác biệt có ý nghĩa thống kê $\mathrm{P}<0.05$.

4.6. Đánh giá tác dụng không mong muốn của phương pháp. Trong điêu trị bệnh lý đau thần kinh toạ do thoát vị đĩa đệm tiêm collagen guna là một trong những phương pháp hiệu quả và an toàn. Trong số 30 bệnh nhân được tiêm collagen guna, không có bệnh nhân nào có phản ứng dị ứng (ngứa sau tiểm) cũng như shock phản vệ, không có bệnh nhân nào đau tăng sau tiêm, không có bệnh nhân nào bị nhiễm trùng tai vị trí tiêm.

Như vậy tiêm collagen điều trị đau thần kinh tọa do thoát vị đĩa đệm nói chung được đảm bảo vô trùng tốt và tương đối an toàn. Tuy nhiên do tất cả các bệnh nhân trong nghiên cứu của chúng tôi đều được thực hiện tại phòng tiêm khớp của đơn nguyên cơ xương khớp bệnh viện đa khoa Đức Giang.

\section{KẾT LUÂ̂N}

Tiêm Collagen trong điều trị đau thần kinh tọa do thoát vị đĩa đệm bước đầu có hiệu quả trong giảm đau, cải thiện chức năng cột sống, chức năng sinh hoạt hàng ngày. Tiêm Collagen hiệu quả và an toàn.

\section{TÀI LIẸU THAM KHẢO}

1. Trần Thái Hà (2007). Đánh giá tác dụng điều trị thoát vị đĩa đệm đĩa đệm cột sống thắt lưng bằng 
phương pháp điện châm, xoa bóp kết hợp vật lý trị liệu, Trường Đại học Y Hà Nội, Hà Nội.

2. H'ô Hữu Lương (2008). Đau thắt lựng và thoát vị đĩa đệm, Nhà xuất bản Y học, Hà Nội, tr 76 - 217.

3. C. Massullo(2017). I Guna Collagen medical device nella ripresa funzionale dopo traumi sportivi case reports.

4. Milani L. A new and refined injectable treatment for musculoskeletal disorder. Bioscaffold properties of collagen and its clinical use. Physiological Regulating Medicine 2010/1; 3-15. 2

5. Raychev I(2013). Efficacy and safety of combined treatment with GuNa MD - Lumbra and GuNa MD - Ishial Collagen injection in patients with lumbar disc hernation.

6. Tsai KS, Kao SY, Wang CY, Wang YJ, WangJP,
Hung SC. Type I collagen promotes proliferation and osteogenesis of human mesenchymal stem cells via activation of ERK and Akt pathways. J Biomed Mater Res A. 2010 Sep l;94(3):673-82.

7. Jeasen GJ., Ponte DJ., Kent BE. (1984). A preliminary report on the use of the Mc Kentzie protocol versus William protocol in the treatment of low back pain. Journal of Orthopaedic and Sport PhysicalcTherapy, Vol.6, No.2, pp 130 - 139.

8. J. Guitart Vela, J. Folch Ibáñez(2016-2017). Collagen MDs for chronic pain. Eficacy and tolerability in chronic treatment in 124 patients.

9. K. Pavelka, R. Svobodová, H. Jarošová (2012) MD-Lumbar, MD-Muscle and MD-Neural in the treatment of low back pain.

\title{
PHÂN TÍCH CHI PHÍ HIỆU QUẢ BẰNG MÔ HÌNH CỦA BUDESONIDE/FORMOTEROL KHI CẦN Ở NGƯỜI BỆNH HEN NHE TẠI VIÊTT NAM
}

\author{
Phạm Huy Tuấn Kiệt ${ }^{1}$, Lê Đặng Tú Nguyên², \\ Heleen van Haalen ${ }^{3}$, Trương Văn Đạt ${ }^{2}$, Lê Hồng Phương ${ }^{4}$, \\ Nguyễn Thị Hải Yến ${ }^{2}$, Nguyễn Thị Quỳnh $\mathrm{Nga}^{2}$
}

\section{TÓM TẮT}

Mục tiêu: Phân tích chi phí-hiệu quả của Budesonide/Formoterol khi cân so với Corticosteroid dang hít (ICS) liều thấp hàng ngày phối hợp với thuốc đồng vân beta giao cảm tác dung ngắn (SÄBA) khi cần ở người bệnh hen phế quản (HPQ) nhẹ tại Việt Nam. Phương pháp nghiên cứu: Mồ hình hóa sử dụng mô hình Markov gồm ba trạng thái chính: không có đợt cấp $\mathrm{HPQ}$, đợt cấp $\mathrm{HPQ}$ nặng, và tử vong. Nghiên cứu được thực hieên dưới quan điểm của cơ quan chi trả, khung thời gian chay mô hình là toàn thời gian sống với chu kỳ của mố hình là một tuân. Hiệu quả lâm sàng được trích xuất từ nghiên cứu SYGMA 2 và các thông số về chi phí được dựa trên một nghiên cứu gánh nặng bệnh tật tại Việt Nam và cơ sở dữ liệu của Cục Quản lý Dược. Kết quả mô hình được biểu thị dưới dạng chỉ số chi phí-hiệu quả tăng thểm (ICER), kết quả phân tích độ nhạy một chiều và phân tích độ nhay xác suất. Kết quả: Budesonide/Formoterol khi cần vượt trội so với phác đồ so sánh, giúp tránh được 0,44 đợt cấp HPQ, tiết kiệm 2.632.464 VNĐ chi phí điêuu trị và tăng $0,0006 \mathrm{QALY} s$ về mặt hiệu quả. Kết quả phân tích độ nhạy một chiều và độ nhạy xác suất đều khẳng định trong đa số trường hợp phân tích, Budesonide/Formoterol khi cân đều đạt chi phí-hiệu

\footnotetext{
${ }^{1}$ Trường Đại học Y Hà Nội

ªại học Y Dược Thành phố Hồ Chí Minh

${ }^{3}$ Công ty AstraZeneca Thụy Điên

${ }^{4}$ Công ty TNHH AstraZeneca Việt Nam

Chịu trách nhiệm chính: Nguyễn Thị Quỳnh Nga

Email: nguyenthiquynhnga@ump.edu.vn

Ngày nhận bài: 17.5.2021

Ngày phản biện khoa học: 29.6.2021

Ngày duyệt bài: 16.7.2021
}

quả. Kết luânn: Từ quan điểm của cơ quan chi trả, Budesonide/Formoterol khi cần tiết kiệm chi phí và tăng hiệu quả so với phác đồ ICS liều thấp phối hợp SABA khi cần về tính chi phí-hiệu quả tại Việt Nam.

Từ khóa: Budesonide/Formoterol, Hen phế quản nhẹ, Phân tích chi phí-hiệu quả

\section{SUMMARY \\ MODELLED COST-EFFECTIVENESS ANALYSIS OF AS-NEEDED BUDESONIDE/FORMOTEROL IN PATIENTS WITH MILD ASTHMA IN VIETNAM}

Objectives: Cost-effectiveness analysis of Budesonide/Formoterol as needed compared with daily low dose inhaled corticosteroids (ICS) in combination with short-acting beta agonists as needed (SABA) in patients with mild asthma in Vietnam. Research methods: A probabilistic Markov cohort model was developed including three main states: non-exacerbation, severe exacerbation, and death. This study was carried out from the payer perspective, with a lifetime horizon and one-week cycle. Clinical parameters were derived from SYGMA 2 trial and costs were extracted from a cost-of-illness study in Vietnam and Drug Administration of Vietnam database. Results were expressed as an incremental cost-effectiveness ratio (ICER), results of one-way sensitivity analysis and probabilistic sensitivity analysis. Results: On average, as needed Budesonide/Formoterol was associated with VND 2,632,464 cost savings, qualityadjusted life year (QALY) gains of 0.0006 and 0.44 exacerbations avoided versus ICS combined with asneeded SABA. Budesonide/Formoterol thus dominated the comparator regarding cost-effectiveness. The results of one-way sensitivity analysis and probabilistic sensitivity analysis confirmed the robustness of the 